\title{
Chronic Stress-Induced Changes in Pro-Inflammatory Cytokines and Spinal Glia Markers in the Rat: A Time Course Study
}

\author{
Viktoriya Golovatscka a, b Helena Ennes ${ }^{a, b}$ Emeran A. Mayer ${ }^{a}$ Sylvie Bradesi ${ }^{a}$ b \\ ${ }^{a}$ Oppenheimer Family Center for Neurobiology of Stress, Division of Digestive Diseases, UCLA David Geffen School of \\ Medicine, and ${ }^{\mathrm{b}}$ GLA VA HS, Los Angeles, Calif., USA
}

\section{Key Words}

Chronic stress - Glia • Pro-inflammatory cytokines · Serum •

Spinal cord visceral pain

\begin{abstract}
Background/Aims: Spinal glia activation has been proposed as one mechanism underlying visceral hyperalgesia in a rodent model of chronic stress. In order to assess the possible role of changes in circulating cytokines and in blood-spinal cord barrier (BSCB) permeability in spinal glia activation, we studied the time course of peripheral and spinal pro-inflammatory cytokines and of spinal and satellite glia markers in response to repeated water avoidance (WA) stress. Methods: Spinal cords and dorsal root ganglion cells (DRGs) were collected from control rats, rats exposed to 1-hour WA, or 1-hour WA daily for 5 days or 1-hour WA daily for 10 days. Results: We demonstrated a time-dependent change in circulating IL-1 $\beta$ and spinal IL-1 $1 \beta$, IL- 6 and TNF- $\alpha$ in stressed animals compared with controls. We found altered expression of the astrocyte markers GFAP and Connexin 43 in spinal and DRG samples at different time points. Finally, WA was associated with increased BSCB permeability. Conclusions: These findings confirm the concept that both peripheral and spinal immune markers are altered after chronic WA and suggest a
\end{abstract}

possible link between stress-induced increase of peripheral pro-inflammatory cytokines, changes in satellite glial cells, increase in BSCB permeability and increase in spinal pro-inflammatory mediators suggesting glia activation.

Copyright $\odot 2012$ S. Karger AG, Basel

\section{Introduction}

Engagement of the central stress system by acute psychological or physical stressors results in activation of the hypothalamic-pituitary-adrenal (HPA) axis and the sympathetic nervous system, including the sympatho-adrenal axis [1]. The resulting increase in circulating glucocorticoids and catecholamine can influence peripheral immune responses [2]. Depending on the nature and duration of the stressor, stress hormones may either inhibit the production of pro-inflammatory cytokines or boost immune responses via the peripheral production of proinflammatory cytokines, including TNF- $\alpha$, IL- $1 \beta$, or IL-6 [3]. Sustained activation of the HPA axis, in association with altered feedback inhibition of the HPA axis response during chronic stress, can lead to disturbance in the balance of pro-inflammatory and anti-inflammatory cytokines.

\section{KARGER}

Fax +41613061234 E-Mail karger@karger.ch www.karger.com
(C) 2012 S. Karger AG, Basel

$1021-7401 / 12 / 0196-0367 \$ 38.00 / 0$

Accessible online at:

www.karger.com/nim
Sylvie Bradesi, PhD

Gail and Gerald Oppenheimer Family Center for Neurobiology of Stress

Division of Digestive Diseases, David Geffen School of Medicine at UCLA

CHS 42-210 MC737818, 10833 Le Conte Avenue, Los Angeles, CA 90095-7378 (USA)

E-Mailsbradesi@ucla.edu 
In the CNS, glial cells, including microglia and astrocytes, play important roles in immunosurveillance of the microenvironment, monitoring cellular debris, apoptotic cells, alterations in neuronal phenotype and balance of synaptic homeostasis [4]. Based on a series of reports showing that different stressors can induce the release of pro-inflammatory cytokines in the CNS $[5,6]$, the concept of a profile of 'cytokine signature' in the CNS in response to stress has been suggested [7] and glia has been proposed as the source of those molecules [8]. While the mechanisms by which stress induces glial secretion of cytokines remain unclear, a role for CNS adrenergic processes has been suggested [9]. Other studies have suggested that stress does not tonically increase pro-inflammatory cytokine levels but triggers a shift in the pro-inflammatory phenotype of microglia and responsiveness to further immune challenge [5].

Pro-inflammatory cytokines are important players in both peripheral and central sensitization as demonstrated in a number of experimental studies showing up-regulation of inflammatory cytokines in models of mechanical or thermal hyperalgesia in rats [10-12]. In humans, IL-1 $\beta$, IL- 6 and TNF- $\alpha$ are elevated after traumatic spinal cord injury [13]. Although the specific triggers of spinal glia reactivity in chronic pain models remain unclear, it is known that glia is reactive in chronic pain conditions and has the capacity to release inflammatory mediators in response to in vitro stimulation with cytokines such as IL-1 $\beta$ [10]. Together, these data suggest a possible interplay between peripheral and CNS inflammatory mediators in the context of chronic pain. Interestingly, recent work has pointed to the possible role of inflammatory cytokines, including IL-1 $\beta$, in the modulation of the blood-brain barrier permeability and the clinical implication of its dysfunction in diseases, including neuropathic pain [14].

In the present study, we propose to assess changes in pro-inflammatory cy tokines in a model of stress-induced exacerbated visceral nociception. Using a validated chronic psychological stress model, e.g. repeated water avoidance (WA) stress, we aimed to test the overall hypothesis that (a) chronic psychological stress leads to increased circulating levels of pro-inflammatory cytokines and changes in dorsal root ganglion (DRG)-satellite glia cell phenotype and (b) the changes in circulating cytokine profile are associated with increased blood-spinal cord barrier (BSCB) permeability and increases in spinal cord pro-inflammatory cytokines are suggestive of glia activation.

\section{Material and Methods}

Adult male Wistar rats (250-275 g; Harlan, Inc.) were maintained on a normal light-dark cycle, and provided with food and water ad libitum. All protocols were approved by the Institutional Animal Care and Use Committee at the VA Greater Los Angeles Healthcare System. All animal experiments were carried out in accordance with the National Institute of Health Guide for the Care and Use of Laboratory Animals (NIH Publications No. 8023, revised 1978).

\section{WA Stress}

The model of chronic WA stress consists in placing each animal on a small platform $(8 \times 8 \times 10 \mathrm{~cm})$ affixed to the center of a Plexiglas cage $(25 \times 25 \times 45 \mathrm{~cm})$ filled with tepid water $\left(25^{\circ} \mathrm{C}\right)$ to within $1 \mathrm{~cm}$ of the top of the platform for $1 \mathrm{~h}$ per session. Animals are not directly exposed to the water and when placed on the platform, avoid the aversive stimulus (water) by remaining on the platform. The rats were placed on the platform and in case they fell, they were immediately removed from the water, dried, and placed again on the platform. The rats learned quickly to avoid the water and never fell more than once or twice and if so, only during the first exposure to the stressor. The model of chronic WA stress (10 days) is a validated model of chronic psychological stress-induced visceral hyperalgesia and has been described in detail previously $[15,16]$.

Five groups of rats were studied: one control group in which rats were handled daily. In another group, rats were exposed to a single 1-hour WA session and sacrificed $1 \mathrm{~h}$ later. A third group was exposed to a single WA for $1 \mathrm{~h}$ but sacrificed $24 \mathrm{~h}$ later. A fourth group was exposed to WA for $1 \mathrm{~h}$ on 5 consecutive days and sacrificed $24 \mathrm{~h}$ later. Finally, a fifth group was exposed to WA for $1 \mathrm{~h}$ on 10 consecutive days and sacrificed $24 \mathrm{~h}$ later. A summary of the experimental groups is provided in figure 1 . At the time of euthanasia, the spinal cords were hydroextruded with iced saline, lumbar L6/S1 spinal segments and DRGs were dissected and processed for Western blotting and enzyme-linked immunosorbent assay (ELISA). Blood samples were collected from the trunk and serums were processed for cytokine measurements using standard ELISA. Different sets of experiments with the same group paradigm (control, $1 \mathrm{~h}$ after $1 \mathrm{WA}, 24 \mathrm{~h}$ after $1 \mathrm{WA}, 24 \mathrm{~h}$ after $5 \mathrm{WA}$ and $24 \mathrm{~h}$ after $10 \mathrm{WA}$ ) were performed for the Evans Blue and FITC-dextran experiments.

\section{Western Blotting}

Spinal cord and DRG samples were transferred to extraction buffer (50 mM Tris buffer, pH 8.0, containing 3\% SDS, 0.5\% Triton $\mathrm{X}-100,150 \mathrm{~mm} \mathrm{NaCl}, 1 \mathrm{~mm}$ EDTA), Protease inhibitor cocktail (1:100; Sigma), and Phosphatase inhibitor cocktail I and II (1:100; Sigma), and immediately homogenized by sonication. $25 \mu \mathrm{g}$ protein was electrophoresed on 3-8\% NuPage Tris-Acetate gels, transferred to polyvinylidene fluoride membranes.

Blots from spinal samples were probed with primary antibodies anti-GFAP (1:65,000; Millipore) [17, 18], anti-Iba1 (1:500; WAKO) [19], and anti-Connexin 43 (1:1,000; Cell Signaling) [20]. Blots from DRG samples were probed with primary antibodies anti-GFAP (1:65,000; Millipore) [17, 18], and anti-Connexin 43 (1:1,000; Cell Signaling) [20]. Membranes were stripped and reblotted with anti-actin (1:1,000; Cell Signaling). The intensity of 
Fig. 1. Schematic diagram illustrating the different groups of animals used in the study. WA: Water avoidance stress.

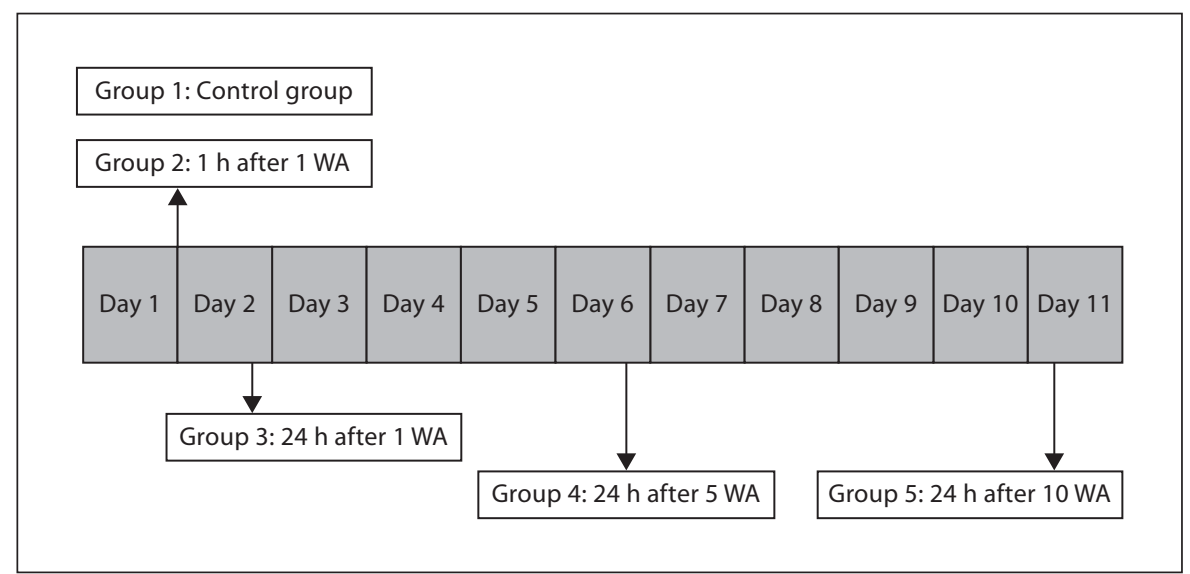

immunoreactive bands was quantified using Image Quant software (Molecular Dynamics, Sunnyvale, Calif., USA) and expressed relative to actin.

\section{Enzyme-Linked Immunosorbent Assay}

Commercially available kits were used to perform ELISA for IL-1 $\beta$, IL-6, and TNF- $\alpha$ (Invitrogen, Camarillo, Calif., USA) [2123]. The sensitivity for each assay was $3 \mathrm{pg} / \mathrm{ml}, 5 \mathrm{pg} / \mathrm{ml}, 4 \mathrm{pg} / \mathrm{ml}$ for IL-1 $\beta$, IL- 6 , and TNF- $\alpha$, respectively. Serum samples were collected from blood $(500 \mu \mathrm{l})$ and centrifuged at 10,000 rpm for 15 $\min$ at $4^{\circ} \mathrm{C}$. Spinal cord and DRG samples were collected and homogenized in buffer $(0.5 \%$ Triton X, $50 \mathrm{~mm}$ Tris, $150 \mathrm{~mm} \mathrm{NaCl}$, $1 \mathrm{~mm}$ EDTA, 1\% SDS). Protein concentration for tissue samples was measured using the standard BCA method (Thermo Scientific, Rockford, Ill., USA). All samples were run in duplicates and absorbance was measured at $450 \mathrm{~nm}$ in a microplate reader (Bio Rad, Model 680).

\section{Measurement of BSCB Permeability}

Groups of stressed rats and controls were assigned to FITCdextran or Evans Blue experiments to assess changes in BSCB permeability.

\section{FITC-Dextran}

Stressed rats from different groups and controls were fasted for $6 \mathrm{~h}$ and gavaged with $4 \mathrm{kDa}$ FITC-labeled dextran diluted in saline (Sigma-Aldrich, St. Louis, Mo., USA; $500 \mathrm{mg} / \mathrm{kg}, 125 \mathrm{mg} / \mathrm{ml}$ ). After $1 \mathrm{~h}$, the rats were sacrificed and the spinal cords were hydroextruded with iced saline, and lumbar L6/S1 spinal segments were isolated and homogenized in PBS. FITC-dextran concentration in homogenates was determined by spectrophotometry (excitation wavelength: $485 \mathrm{~nm}$; emission wavelength: $535 \mathrm{~nm}$; SpectraMax M2; Molecular Devices, Sunnyvale, Calif., USA). The size of FITC-dextran is $4 \mathrm{kDa}$ and its passage into the spinal cord (after permeation into the blood) is indicative of permeability to small molecules of similar size.

Evans Blue Assay

BSCB permeability was determined by Evans Blue extravasation into the spinal cord in separate groups of stressed and control rats. Evans Blue dye $(2 \%, 4 \mathrm{ml} / \mathrm{kg})$ was infused through the jugu- lar vein of anaesthetized rats. After $45 \mathrm{~min}$, the animals were perfused via a cardiac perfusion with PBS. Spinal cord tissues were immediately hydroextruded with iced saline and the lumbar spinal cord (L6/S1) was dissected. Tissues were incubated in $600 \mu \mathrm{l}$ formamide (Sigma-Aldrich) at $60^{\circ} \mathrm{C}$ for $72 \mathrm{~h}$. Evans Blue concentration was then determined by spectrophotometry at $620 \mathrm{~nm}$. Evans Blue is known to bind to albumin and its passage into the spinal cord is representative of the passage of molecules of sizes close to $68 \mathrm{kDa}$ and lower.

\section{Statistical Analysis}

Data from control rats were normalized to $100 \%$ and data from stressed animals were expressed as percentages of the control response. Data were tested for normal distribution using the Kolmogorov-Smirnov normality test and were analyzed using a oneway ANOVA followed by Dunnett's post-test comparing all groups to the control. Correlation studies between different markers were not possible because each time point corresponded to a different group of rats.

\section{Results}

\section{Stress Induced Changes in Plasma Cytokines}

A one-way ANOVA was used to test the effect of time on plasma cytokine levels. Serum levels of IL-1 $\beta$ were significantly different across time, $\mathrm{F}(4,42)=6.095(\mathrm{p}=$ 0.006). Dunnett's post-hoc comparisons indicated that the serum levels of IL-1 $\beta$ at $1 \mathrm{~h}(126.9 \pm 9.4, \mathrm{p}<0.05)$, $24 \mathrm{~h}$ after $1 \mathrm{WA}(127.9 \pm 6, \mathrm{p}<0.05)$ and $24 \mathrm{~h}$ after 5 WA $(121.3 \pm 6.5, \mathrm{p}<0.05)$ were significantly increased compared with non-stressed controls (100 $\pm 3.9 ; \mathrm{n}=$ 6-12/group; fig. 2a). However, the levels of circulating IL- 6 and TNF- $\alpha$ were not significantly different in any of the stressed groups compared with controls (for IL-6: $\mathrm{n}=$ 6-12/group and for TNF- $\alpha: n=6-12$ /group; fig. $2 b, c)$. The absolute plasma cytokine levels were within the 


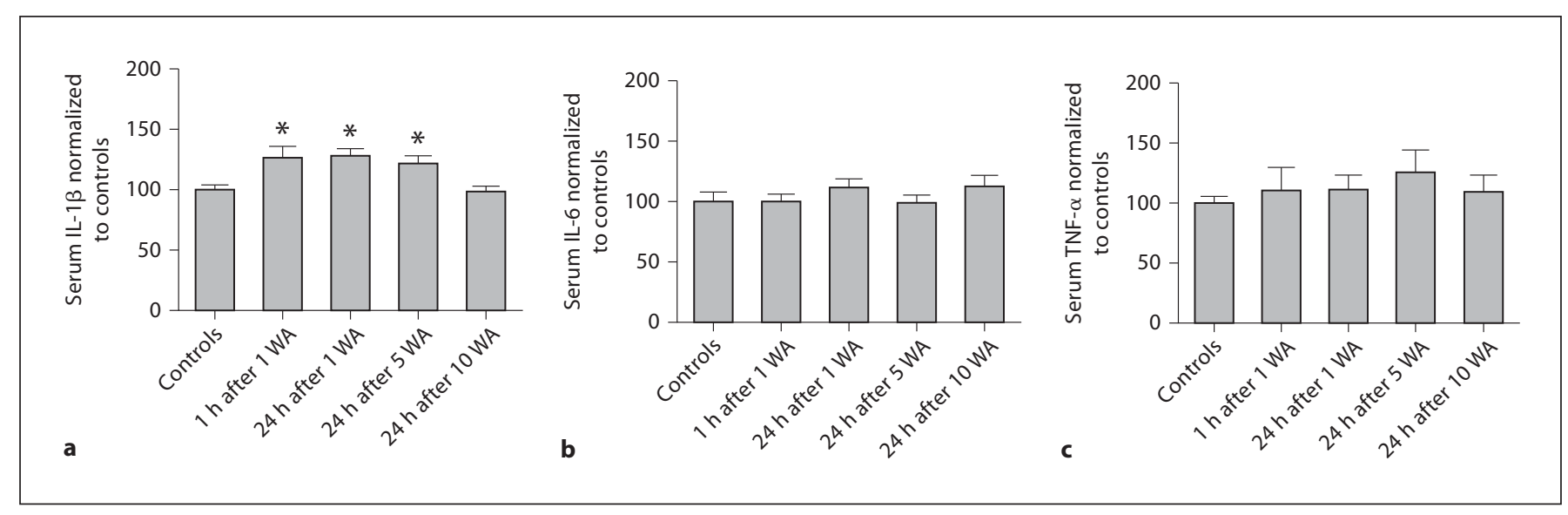

Fig. 2. Plasma cytokine levels measured by ELISA. a Circulating level of IL-1 $\beta, n=6-12$ in each group, ${ }^{*} p<$ 0.05 , significantly different from controls, ANOVA followed by Dunnett's test. $\mathbf{b}$ Circulating level of IL- $6, \mathrm{n}=$ 6-12 in each group. c Circulating level of TNF- $\alpha, \mathrm{n}=6-11$. Data are means \pm SEM normalized to controls.

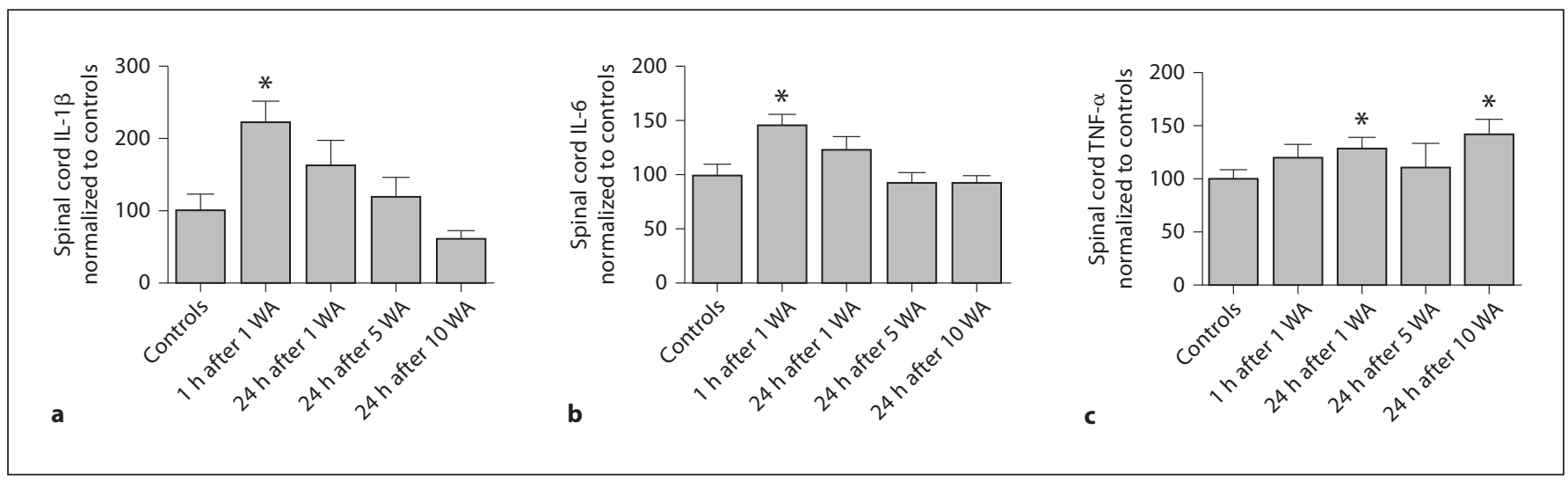

Fig. 3. Spinal cord cytokine levels measured by ELISA. a Spinal cord level of IL-1 $\beta, n=6-12$ in each group. b Spinal cord level of IL-6, $n=6-12$ in each group. c Spinal cord level of TNF- $\alpha, n=6-12$. Data are means \pm SEM normalized to controls. ${ }^{*} \mathrm{p}<0.05$, significantly different from controls, ANOVA followed by Dunnett's test.

range described in previous papers $[24,25]$ with lower values of $43.7 \pm 3 \mathrm{pg} / \mathrm{ml}$ for IL- $1 \beta, 42.6 \pm 5 \mathrm{pg} / \mathrm{ml}$ for IL- 6 and $24.8 \pm 3 \mathrm{pg} / \mathrm{ml}$ for TNF- $\alpha$.

\section{Cytokines in the Spinal Cord}

The levels of IL-1 $\beta$, TNF- $\alpha$ and IL- 6 were assessed in spinal cord extracts from the 5 groups. A one-way ANOVA was used to test the effect of time on spinal cytokine expression. The spinal level of IL-1 $\beta$ varied depending on time, $\mathrm{F}(4,47)=4.033(\mathrm{p}=0.0068)$. Dunnett's post-hoc comparisons indicated that IL-1 $\beta$ was significantly increased at $1 \mathrm{~h}$ after $1 \mathrm{WA}(222.8 \pm 29.1)$ compared with controls $(100 \pm 22.4, \mathrm{p}<0.05 ; \mathrm{n}=6-12$ /group; fig. 3a). Similarly, IL-6 varied depending on time, $F(4,40)=3.448$ $(\mathrm{p}=0.0164)$. Dunnett's post-hoc comparisons indicated that IL-6 was significantly higher $1 \mathrm{~h}$ after $1 \mathrm{WA}(145.5$ $\pm 10.6)$ compared with controls $(100 \pm 9.9, \mathrm{p}<0.05 ; \mathrm{n}=$ 6-12/group; fig. 3b) There was no significant difference in the expression of IL-1 $\beta$ and IL- 6 at any other time points compared with controls. The level of spinal TNF- $\alpha$ varied depending on time, $\mathrm{F}(4,42)=4.457(\mathrm{p}=0.0043)$. Dunnett's post-hoc comparisons indicated that spinal TNF- $\alpha$ was increased at $24 \mathrm{~h}$ after 1 WA $(128.2 \pm 11.1)$ and at $24 \mathrm{~h}$ after $10 \mathrm{WA}(141.6 \pm 14.6)$ compared with 


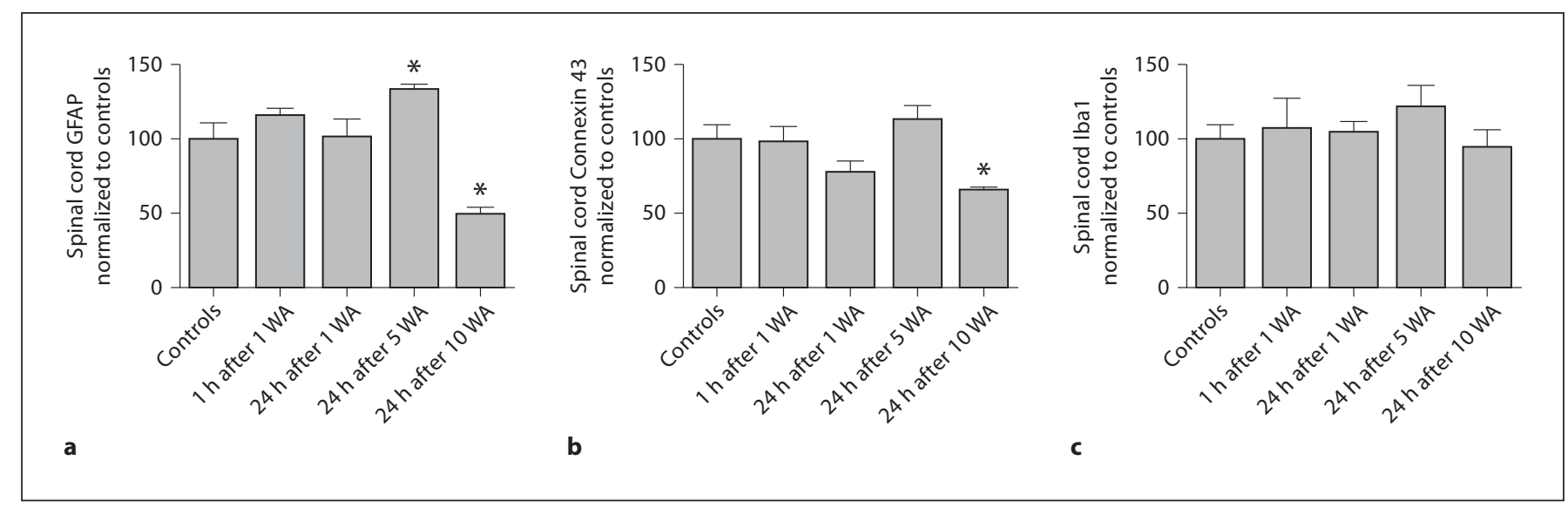

Fig. 4. Protein expression in spinal cord extracts measured by Western blotting. a Spinal cord level of GFAP, $n=6-12$. b Spinal cord level of Connexin 43 (Cn43), $n=6-12$. c Spinal cord level of Iba1, $\mathrm{n}=6-12$. Data are means \pm SEM normalized to controls. ${ }^{*} \mathrm{p}<0.05$, significantly different from controls, ANOVA followed by Dunnett's test. $\mathbf{d}$ Representative blots.

controls ( $100 \pm 8.3, \mathrm{p}<0.05 ; \mathrm{n}=6-12$ /group; fig. $3 \mathrm{c})$. The absolute spinal cytokine levels were within the range described in previous papers $[23,26]$ with lower values of $5.3 \pm 0.7 \mathrm{pg} / \mathrm{ml}$ for IL- $1 \beta, 7.5 \pm 1 \mathrm{pg} / \mathrm{ml}$ for IL- 6 and 5.0 $\pm 1 \mathrm{pg} / \mathrm{ml}$ for TNF- $\alpha$.

\section{GFAP, Iba1 and Connexin 43 in the Spinal Cord and}

$D R G s$

In the spinal cord, a one-way ANOVA showed changes in GFAP across time, $\mathrm{F}(4,44)=9.733(\mathrm{p}=0.0001)$. Dunnett's post-hoc comparisons showed an increased level of GFAP observed $24 \mathrm{~h}$ after 5 WA $(133.6 \pm 3.7, \mathrm{p}<0.05)$, while a significant decrease was found $24 \mathrm{~h}$ after $10 \mathrm{WA}$ $(50 \pm 4.2, \mathrm{p}<0.05)$ compared with controls $(100 \pm 11.1$; $\mathrm{n}=6-12$ /group; fig. 4a). Connexin 43 significantly changed across time, $\mathrm{F}(4,31)=5.240(\mathrm{p}=0.0024)$, and a Dunnett's post-hoc comparisons showed the level at $24 \mathrm{~h}$ after 10 WA was decreased to $66.3 \pm 1.7$ compared with controls (100 $\pm 9.9, \mathrm{p}<0.05 ; \mathrm{n}=6-12$ /group; fig. 4b). Iba1 showed no changes in the stressed groups compared with controls ( $n=6-12 /$ group; fig. 4c). Representative blots for each time point are presented in figure $4 \mathrm{~d}$.

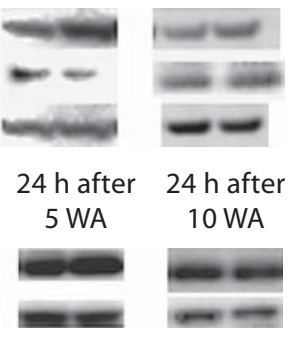

In DRGs, a one-way ANOVA showed changes in GFAP across time, $\mathrm{F}(4,31)=5.504(\mathrm{p}=0.0018)$. Dunnett's posthoc comparisons revealed that GFAP was dramatically increased $24 \mathrm{~h}$ after $10 \mathrm{WA}(315.3 \pm 67.5)$ compared with controls $(100 \pm 21.35, \mathrm{p}<0.01 ; \mathrm{n}=6-10$ /group; fig. 5a), while Connexin 43 was significantly increased $24 \mathrm{~h}$ after 5 WA (168 \pm 18.35$)$ compared with controls (100 \pm 13.4 , $\mathrm{p}<0.05 ; \mathrm{F}(4,31)=2.809, \mathrm{p}=0.0424 ; \mathrm{n}=6-10 /$ group; fig. $5 b)$. Representative blots for each time point are presented in figure $5 c$.

\section{Stress Induced Changes in BSCB Permeability}

A one-way ANOVA revealed that Evans Blue concentration varied in the different groups, $\mathrm{F}(4,32)=4.374$ $(\mathrm{p}=0.0062)$. Dunnett's post-hoc comparisons showed an increased concentration at $24 \mathrm{~h}$ after 5 WA sessions $(9.5 \pm 1.5)$ compared with controls $(4.84 \pm 0.3, \mathrm{p}<0.05)$, suggesting an increased permeability to molecules of a size comparable to albumin (fig. 6a). There was no significant difference between the other stress groups and controls ( $n=5-9 /$ group). In a different series of experiments, the concentration of FITC-dextran was signifi- 
Fig. 5. Protein expression in DRG extracts measured by Western blotting. a DRG level of GFAP, $n=6-10$. b DRG level of Connexin $43(\mathrm{Cn} 43), \mathrm{n}=6-10$. Data are means \pm SEM normalized to controls. ${ }^{*} \mathrm{p}<0.05$, ** $\mathrm{p}<0.01$, significantly different from controls, ANOVA followed by Dunnett's test. c Representative blots.
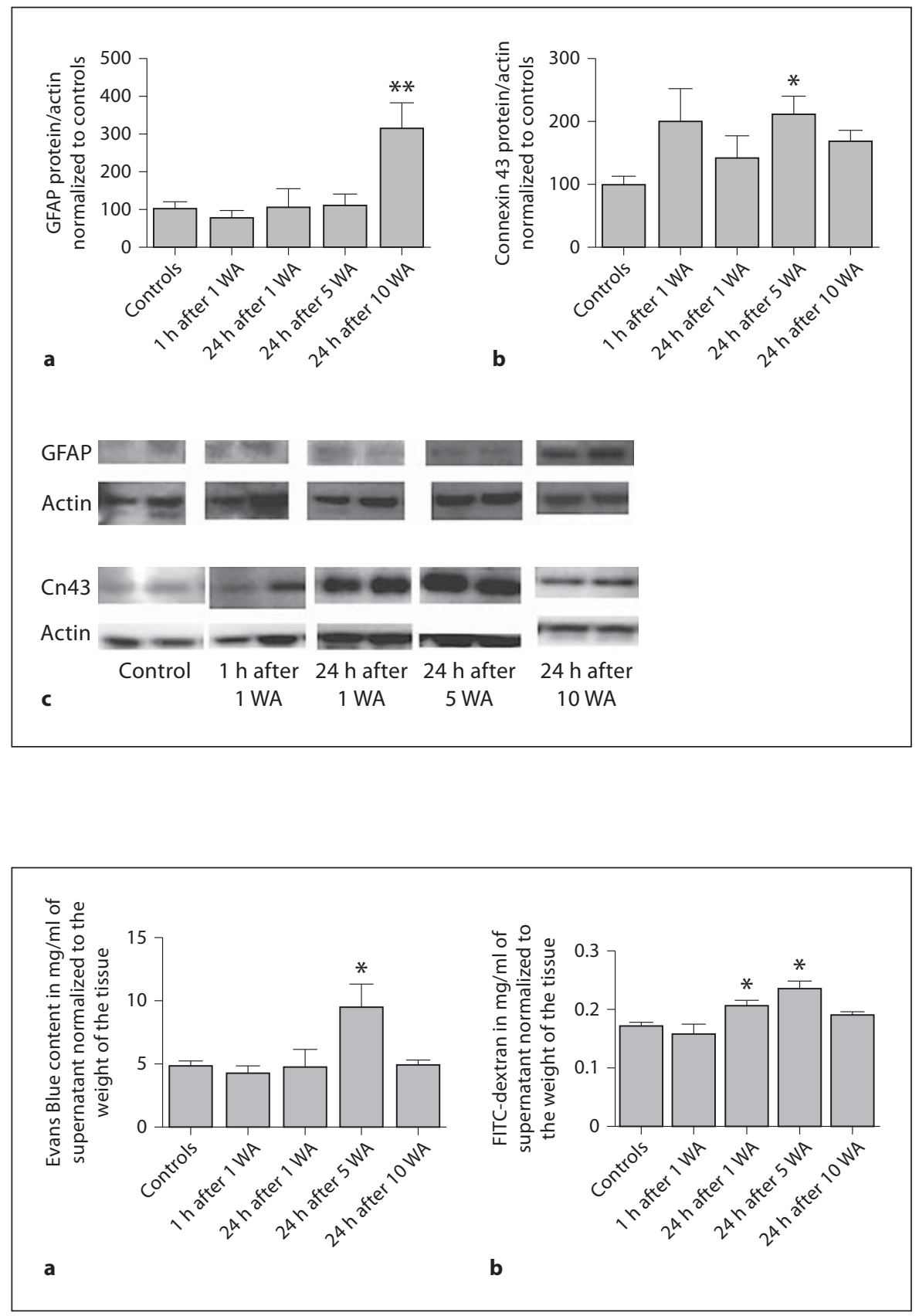

Fig. 6. Measures of blood-spinal cord permeability a Evans Blue extravasation in the spinal cord, $n=5-9$. b FITC-dextran extravasation in the spinal cord, $\mathrm{n}=6-11$. Data are means \pm SEM normalized to controls. ${ }^{*} \mathrm{p}<0.05$, significantly different from controls, ANOVA followed by Dunnett's test.

\section{Discussion}

In the present study, we were able to demonstrate a time-dependent profile in the levels of circulating IL-1 $\beta$ and spinal IL-1 $\beta$, IL- 6 and TNF- $\alpha$ in stressed animals compared with non-stressed controls. In addition, we found temporal changes in the expression of the astrocytic marker GFAP in spinal and DRG samples. We also 
identified that WA stress is associated with a transient increase in BSCB permeability.

We reported an increased plasma concentration of IL$1 \beta$ at $1 \mathrm{~h}$ after $1 \mathrm{WA}, 24 \mathrm{~h}$ after $1 \mathrm{WA}$ and $24 \mathrm{~h}$ after $5 \mathrm{WA}$. We found no changes in other circulating pro-inflammatory cytokines (IL-6 and TNF- $\alpha$ ) in response to stress at any time points. These results point towards a rapid increase in IL-1 $\beta$ in the circulation in response to a single stress session (within 1-24 h after 1 WA stress session), which seems to be maintained after 5 WA sessions. The changes in circulating IL-1 $\beta$ were significant $(p<0.05)$ though it should be noted that the amplitude of the changes does not correspond to an inflammatory profile' per se as can be seen in models of peripheral inflammation for example [27]. These findings are consistent with other reports showing that, while the effect of stress on the immune system and the pattern of stress-induced cytokine increase in the circulation and in the CNS is depending on the nature of the stressor, IL-1 $\beta$ appears to be one key cytokine that is consistently increased after stress exposure in both blood and brain in several stress models $[28,29]$. It is unlikely that circulating IL- $1 \beta$ originates from a peripheral site of inflammation or injury since we previously demonstrated that the model of chronic WA stress is not associated with significant gastrointestinal structural alterations or inflammation [30]. However, it is possible that our results reflect a cell-mediated immune response to stress as described in other studies [31]. The effect of stress on cell-mediated immune response may include trafficking or redistribution of peripheral lymphocytes between different immune compartments, including the spleen, in which changes in the expression of cell adhesion molecules plays a significant role [32]. Although we did not measure circulating lymphocytes or cytokines from extracted circulating lymphocytes, it is possible that they contribute to the increased circulating IL-1 $\beta$ in our stress model [33]. Cytokines in the blood may also originate from chromaffin cells of the adrenal medulla [34], or may derive from high CNS concentrations [35].

In the spinal cord, we observed increased concentrations of IL- $1 \beta$ and IL- 6 at $1 \mathrm{~h}$ after 1 WA only, while TNF$\alpha$ was increased $24 \mathrm{~h}$ after $1 \mathrm{WA}$ and $24 \mathrm{~h}$ after $10 \mathrm{WA}$ only. Our results point towards a rapid and transient increase in pro-inflammatory mediators in the spinal cord in response to a single stress session (within 1-24 h after 1 WA stress session), while the only cytokine showing changes after 10 days of stress was TNF- $\alpha$. This cytokine profile in the spinal cord does not reflect the changes of IL-1 $\beta$ observed in the serum from day 1 to $24 \mathrm{~h}$ after day
5 , suggesting the lack of direct peripheral origin of spinal cytokines. In the CNS, cytokines may be of neuronal or glial origins (including microglia and astrocytes) and play an important role in the sensitization of nociceptive signals [36]. In the present study, our data showed no changes in the protein level of Ibal at any time point (commonly used as one marker of microglia). However, we have previously demonstrated that chronic WA stress leads to p38 activation in spinal microglia $24 \mathrm{~h}$ after 10 WA and that spinal microglia play a functional role in the expression of visceral hyperalgesia [18]. In addition, previous studies have reported the potential of glia to release mediators without change in Ibal phenotype $[37,38]$. It is also known that stress alone can promote glia activation in the CNS, or prime glia to further stimulation [8]. Our present results also showed a biphasic change in GFAP expression with an increased GFAP protein level $24 \mathrm{~h}$ after 5 WA followed by a decreased level compared with controls $24 \mathrm{~h}$ after $10 \mathrm{WA}$. These results are consistent with our previous findings showing a decreased GFAP protein level and GFAP immunohistochemistry intensity $24 \mathrm{~h}$ after $10 \mathrm{WA}$ [36]. Together, these results suggest a possible implication of spinal glia activation and the release of glia mediators in the CNS immune response to chronic stress. We also found decreased spinal glutamate transporter expressions after stress and supporting evidence for a role of the glutamatergic system in our model [18].

IL-1 $\beta$ and TNF- $\alpha$ have been implicated in the pathophysiological changes occurring in various disease states, including rheumatoid arthritis, neuropathic pain or inflammatory bowel disorders $[35,39]$. In the spinal cord, the central role of IL-1 $\beta$ to the development of chronic pain is well established [40-42]. Elevated spinal IL-1 $\beta$ was reported in both human [13] and rat [43] following spinal cord injury. It has been proposed that the pro-nociceptive effect of IL-1 $\beta$ is mediated through the up-regulation of other pro-nociceptive mediators (NGF, CGRP) or the modulation of neuronal excitability by affecting receptors such as TRPV1, sodium channels, GABA or NMDA receptors. In a recent paper, spinal IL- $1 \beta$ released from astrocytes was found to enhance NR1 phosphorylation to facilitate inflammatory pain [44]. Similarly, increasing evidence suggest a critical role of TNF- $\alpha$ in the pathogenesis of pain, including neuropathic pain and inflammatory pain; and while the peripheral effect of TNF$\alpha$ on nociceptor sensitization is well established [45], the role of TNF- $\alpha$ in central sensitization is increasingly supported by a growing literature. TNF- $\alpha$ expression is induced in spinal cord glial cells in several models of chron- 
ic pain [46], and intrathecal injections of TNF- $\alpha$ or a TNF- $\alpha$ inhibitor have been found to trigger and inhibit hyperalgesic response, respectively $[12,39]$. Recent work identified the critical role of TNF- $\alpha$ in spinal synaptic activity and in the control of NMDAR activity [12].

In the chronic WA stress model, TNF- $\alpha$ is increased in the spinal cord $24 \mathrm{~h}$ after $1 \mathrm{WA}$ and $24 \mathrm{~h}$ after $10 \mathrm{WA}$. Interestingly, these 2 time points correspond to the time points at which we previously reported visceral hyperalgesia $[30,47]$ suggesting a possible link between spinal TNF- $\alpha$ and stress-induced sensitization of visceral nociception. Although our study is limited by (1) the lack of statistical correlation between the level of TNF- $\alpha$ and visceral hyperalgesia (observations in different rat groups from different experiments precluding correlation analysis) and (2) the lack of pharmacological studies evaluating the role of cytokine inhibitors on peripheral and spinal markers and visceral sensitivity, one may speculate about the role of IL- $1 \beta$ and TNF- $\alpha$ in the modulation of the visceral nociceptive response. Further mechanistic studies using transgenic animals or testing the effects of cytokine receptor antagonists or blocking antibodies are warranted to confirm this hypothesis.

While glia is accepted as a potential source of cytokines in the CNS, it remains unclear what signals are causing glia activation and release of pro-inflammatory cytokines, in particular in models of stress-induced CNS glia activation. Evidence exists supporting the ability of peripheral cytokines to transduce their signals across the blood-brain barrier (BBB) [48], and thereby, triggering a series of signaling pathways in the CNS. This has been described for IL-1 $\beta$ which is thought to induce the elevation of CNS IL-1 $\beta$ through several indirect mechanisms such as stimulation of vagal or other nerve afferents [49, 50], immune cell trafficking from blood to brain with subsequent secretion [51], induction of mediators release from BBB cells [52], interaction with circumventricular organs [53] or directly crossing the BBB. In a recent paper [54], it was demonstrated that regional neural activation defined a gateway for autoreactive $\mathrm{T}$ cells to cross the BBB via an effect of IL- 6 in endothelial cells in the spinal cord supporting a role for neural mechanisms in neuroimmune activation in the CNS.

In our study, we found a simultaneous increase in IL$1 \beta$ in the circulation and in the spinal cord in the early stress exposure, with increased circulating IL-1 $\beta$ outlasting changes in spinal IL-1 $\beta$. In view of these results, it is difficult to conclude whether peripheral IL-1 $\beta$ may be a triggering factor in the increase of spinal IL-1 $\beta$. However, it is possible that an increase in spinal TNF- $\alpha$ (which oc- curred only at $24 \mathrm{~h}$ after $1 \mathrm{WA}$ and $24 \mathrm{~h}$ after $10 \mathrm{WA}$ ) may be consecutive to the transduction of peripheral IL- $1 \beta$ signals from the periphery to the CNS. This is supported by our observations that the BSCB permeability is increased in our model of chronic WA stress at $24 \mathrm{~h}$ after $1 \mathrm{WA}$. We showed increased permeability to small molecules $(4 \mathrm{kDa})$ $24 \mathrm{~h}$ after $1 \mathrm{WA}$ and $24 \mathrm{~h}$ after $5 \mathrm{WA}$, while permeability to Evans Blue (which binds to albumin $(68 \mathrm{kDa})$ ) was significantly increased $24 \mathrm{~h}$ after 5 WA (which may be connected to the prior passage of smaller molecules enabled $24 \mathrm{~h}$ after $1 \mathrm{WA}$ ). Surprisingly, the significant increase of BSCB permeability to large molecules matched the increased expression of spinal GFAP at $24 \mathrm{~h}$ after $5 \mathrm{WA}$. It is possible that changes in astrocyte phenotypes, although associated with increased GFAP, may influence BSCB permeability at day 5. The role of Connexin 43 (a gap junction protein involved in astrocyte networking) in the control of BBB permeability has been previously discussed [55]. However, while Connexin 43 is predominantly associated with astrocytic gap junctions, Connexin 43 in endothelial cells may have cell autonomous effects on their responses to permeability-enhancing signals, independent of any effects on intercellular communication (colocalization with the tight junction molecules occludin, claudin, and ZO-1) [56], which may explain the different time course observed for stress-induced changes in BSCB permeability and changes in expression of spinal Connexin 43 and GFAP in our model after 10 WA.

Our findings, showing a trend for sustained increased levels of Connexin 43 in DRGs throughout the $10 \mathrm{WA}$ period and significantly higher levels of GFAP at $24 \mathrm{~h}$ after 10 WA in DRGs, suggest that satellite glia cells (SGCs, glial cells present in sensory neurons in DRGs) may respond to input from either spinal or peripheral origin. It has been previously observed that increased gap junction-mediated coupling between SGCs (as indicated by increased Connexin 43 expression) contributes to increased sensory neuron coupling and augmented neuronal excitability. Interestingly, SGCs were also found capable of releasing cytokines such as IL- $1 \beta$ and TNF- $\alpha[57$, 58]. Although the sensitization of DRG neurons is well documented in rat models of visceral pain induced by inflammation [59], the role of SGCs in visceral pain has received little attention. A recent study showed that gap junction blockers injected directly into DRGs abolish colonic inflammation-induced changes in SGCs and sensory neurons and significantly reverse visceral pain behavior, suggesting a role of SGCs in the modulation of visceral nociception after inflammation [60]. Our data indicate SGCs activation and increased coupling, sug- 
gested by increased Connexin 43 in response to chronic WA stress in DRGs. The role of these changes in spinal glia activation and increase in visceral nociception in the chronic WA stress model needs to be further investigated.

In conclusion, the present study establishes a profile of circulating and spinal cytokines during the course of 10 days WA stress associated with changes in spinal astrocytes, BSCB permeability, and DRG SGC activation. While the data provide a mostly descriptive analysis of those changes, they also provide the necessary framework to further evaluate the functional role of peripheral and spinal cytokines in stress-induced spinal glia activation and the development of visceral hyperalgesia.

\section{Acknowledgement}

We received grant support from the NIH (NIH RO1 DA026597$01 \mathrm{~A} 2$ to $\mathrm{S}$. Bradesi).

\section{Disclosure Statement}

The authors report no conflicts of interest. The authors alone are responsible for the content and writing of the paper.

\section{References}

-1 Elenkov IJ, Wilder RL, Chrousos GP, Vizi ES: The sympathetic nerve - an integrative interface between two supersystems: the brain and the immune system. Pharmacol Rev 2000;52:595-638.

2 Chrousos GP: The hypothalamic-pituitaryadrenal axis and immune-mediated inflammation. N Engl J Med 1995;332:1351-1362.

-3 Elenkov IJ, Chrousos GP: Stress hormones, proinflammatory and antiinflammatory cytokines, and autoimmunity. Ann NY Acad Sci 2002;966:290-303.

-4 Watkins LR, Milligan ED, Maier SF: Glial activation: a driving force for pathological pain. Trends Neurosci 2001;24:450-455.

5 Frank MG, Baratta MV, Sprunger DB, Watkins LR, Maier SF: Microglia serve as a neuroimmune substrate for stress-induced potentiation of CNS pro-inflammatory cytokine responses. Brain Behav Immun 2007;21: 47-59.

-6 Maken DS, Weinberg J, Cool DR, Hennessy MB: An investigation of the effects of maternal separation and novelty on central mechanisms mediating pituitary-adrenal activity in infant guinea pigs (cavia porcellus). Behav Neurosci 2011;124:800-809.

7 Anisman H: Cascading effects of stressors and inflammatory immune system activation: implications for major depressive disorder. J Psychiatry Neurosci 2009;34:4-20.

-8 Frank MG, Watkins LR, Maier SF: Stressand glucocorticoid-induced priming of neuroinflammatory responses: potential mechanisms of stress-induced vulnerability to drugs of abuse. Brain Behav Immun 2011; 25(suppl 1):S21-S28.

$\checkmark 9$ Wohleb ES, Hanke ML, Corona AW, Powell ND, Stiner LM, Bailey MT, Nelson RJ, Godbout JP, Sheridan JF: Beta-adrenergic receptor antagonism prevents anxiety-like behavior and microglial reactivity induced by repeated social defeat. J Neurosci 2011;31: $6277-6288$
10 Rothman SM, Nicholson KJ, Winkelstein BA: Time-dependent mechanics and measures of glial activation and behavioral sensitivity in a rodent model of radiculopathy. J Neurotrauma 2010;27:803-814.

11 Raghavendra V, Tanga FY, DeLeo JA: Complete freunds adjuvant-induced peripheral inflammation evokes glial activation and proinflammatory cytokine expression in the CNS. Eur J Neurosci 2004;20:467-473.

12 Zhang L, Berta T, Xu ZZ, Liu T, Park JY, Ji RR: TNF-alpha contributes to spinal cord synaptic plasticity and inflammatory pain: distinct role of TNF receptor subtypes 1 and 2. Pain 2011;152:419-427.

13 Yang L, Blumbergs PC, Jones NR, Manavis J, Sarvestani GT, Ghabriel MN: Early expression and cellular localization of proinflammatory cytokines interleukin-1beta, interleukin-6, and tumor necrosis factor-alpha in human traumatic spinal cord injury. Spine (Phila Pa 1976) 2004;29:966-971.

14 Echeverry S, Shi XQ, Rivest S, Zhang J: Peripheral nerve injury alters blood-spinal cord barrier functional and molecular integrity through a selective inflammatory pathway. J Neurosci 2011;31:10819-10828.

15 Bradesi S, Schwetz I, Ennes HS, Lamy CM, Ohning G, Fanselow M, Pothoulakis C, McRoberts JA, Mayer EA: Repeated exposure to water avoidance stress in rats: a new model for sustained visceral hyperalgesia. Am J Physiol Gastrointest Liver Physiol 2005;289:G42-G53.

16 Million M, Taché Y, Anton P: Susceptibility of Lewis and Fisher rats to stress-induced worsening of TNB-colitis: protective role of brain CRF. Am J Physiol Gastrointest Liver Physiol 1999;276:G1027-G1036.

17 Svensson CI, Hua XY, Protter AA, Powell HC, Yaksh TL: Spinal p38 map kinase is necessary for nmda-induced spinal pge(2) release and thermal hyperalgesia. Neuroreport 2003;14:1153-1157.
18 Bradesi S, Golovatscka V, Ennes HS, McRoberts JA, Karagiannides I, Bakirtzi K, Pothoulakis C, Mayer EA: Role of astrocytes and altered regulation of spinal glutamatergic neurotransmission in stress-induced visceral hyperalgesia in rats. Am J Physiol Gastrointest Liver Physiol 2011;301:G580-G589.

19 Matsui T, Svensson CI, Hirata Y, Mizobata K, Hua XY, Yaksh TL: Release of prostaglandin $\mathrm{e}(2)$ and nitric oxide from spinal microglia is dependent on activation of p38 mitogen-activated protein kinase. Anesth Analg 2010; 111:554-560

20 Lutz SE, Zhao Y, Gulinello M, Lee SC, Raine CS, Brosnan CF: Deletion of astrocyte connexins 43 and 30 leads to a dysmyelinating phenotype and hippocampal cal vacuolation. J Neurosci 2009;29:7743-7752.

-21 Lu PP, Liu JT, Liu N, Guo F, Ji YY, Pang X: Pro-inflammatory effect of fibrinogen and FDP on vascular smooth muscle cells by IL6, TNF-alpha and iNOS. Life Sci 2011;88: 839-845

22 Riazi K, Galic MA, Kuzmiski JB, Ho W, Sharkey KA, Pittman QJ: Microglial activation and TNFalpha production mediate altered CNS excitability following peripheral inflammation. Proc Natl Acad Sci USA 2008; 105:17151-17156.

-23 Sweitzer S, Martin D, DeLeo JA: Intrathecal interleukin-1 receptor antagonist in combination with soluble tumor necrosis factor receptor exhibits an anti-allodynic action in a rat model of neuropathic pain. Neuroscience 2001;103:529-539.

24 Davey KJ, O’Mahony SM, Schellekens H, O'Sullivan O, Bienenstock J, Cotter PD, Dinan TG, Cryan JF: Gender-dependent consequences of chronic olanzapine in the rat: effects on body weight, inflammatory, metabolic and microbiota parameters. Psychopharmacology (Berl) 2012;221:155-169. 
-25 Chennaoui M, Drogou C, Gomez-Merino D: Effects of physical training on IL-1beta, IL-6 and IL-1ra concentrations in various brain areas of the rat. Eur Cytokine Netw 2008;19: 8-14.

-26 Loram LC, Taylor FR, Strand KA, Frank MG, Sholar P, Harrison JA, Maier SF, Watkins LR: Prior exposure to glucocorticoids potentiates lipopolysaccharide induced mechanical allodynia and spinal neuroinflammation. Brain Behav Immun 2011;25:1408-1415.

-27 Watanabe M, Guo W, Zou S, Sugiyo S, Dubner R, Ren K: Antibody array analysis of peripheral and blood cytokine levels in rats after masseter inflammation. Neurosci Lett 2005;382:128-133.

-28 Nguyen KT, Deak T, Will MJ, Hansen MK, Hunsaker BN, Fleshner M, Watkins LR, Maier SF: Timecourse and corticosterone sensitivity of the brain, pituitary, and serum interleukin-1beta protein response to acute stress. Brain Res 2000;859:193-201.

-29 O'Connor KA, Johnson JD, Hansen MK, Wieseler Frank JL, Maksimova E, Watkins LR, Maier SF: Peripheral and central proinflammatory cytokine response to a severe acute stressor. Brain Res 2003;991:123-132.

-30 Bradesi S, Schwetz I, Ennes HS, Lamy CM, Ohning G, Fanselow M, Pothoulakis C, McRoberts JA, Mayer EA: Repeated exposure to water avoidance stress in rats: a new model for sustained visceral hyperalgesia. Am J Physiol Gastrointest Liver Physiol 2005;289:G42-G53.

>31 Dhabhar FS, Miller AH, McEwen BS, Spencer RL: Effects of stress on immune cell distribution. Dynamics and hormonal mechanisms. J Immunol 1995; 154:5511-5527.

-32 Bauer ME, Perks P, Lightman SL, Shanks N: Are adhesion molecules involved in stressinduced changes in lymphocyte distribution? Life Sci 2001;69:1167-1179.

$\checkmark 33$ Edgar VA, Silberman DM, Cremaschi GA, Zieher LM, Genaro AM: Altered lymphocyte catecholamine reactivity in mice subjected to chronic mild stress. Biochem Pharmacol 2003;65:15-23.

-34 Nunez L, De La Fuente MT, Garcia AG, Garcia-Sancho J: Differential Ca2+ responses of adrenergic and noradrenergic chromaffin cells to various secretagogues. Am J Physiol 1995;269:C1540-C1546.

>35 Ren K, Torres R: Role of interleukin-1beta during pain and inflammation. Brain Res Rev 2009;60:57-64.

36 Watkins LR, Milligan ED, Maier SF: Glial proinflammatory cytokines mediate exaggerated pain states: implications for clinical pain. Adv Exp Med Biol 2003;521:1-21.
7 Svensson CI, Fitzsimmons B, Azizi S, Powell HC, Hua XY, Yaksh TL: Spinal p38beta isoform mediates tissue injury-induced hyperalgesia and spinal sensitization. J Neurochem 2005;92:1508-1520.

38 Nimmerjahn A, Kirchhoff F, Helmchen F: Resting microglial cells are highly dynamic surveillants of brain parenchyma in vivo. Science 2005;308:1314-1318.

-39 Andrade P, Visser-Vandewalle V, Hoffmann C, Steinbusch HW, Daemen MA, Hoogland G: Role of TNF-alpha during central sensitization in preclinical studies. Neurol Sci 2011 32:757-771.

40 Scholz J, Woolf CJ: The neuropathic pain triad: neurons, immune cells and glia. Nat Neurosci 2007;10:1361-1368.

41 Shavit Y, Wolf G, Goshen I, Livshits D, Yirmiya R: Interleukin-1 antagonizes morphine analgesia and underlies morphine tolerance. Pain 2005;115:50-59.

42 Reeve AJ, Patel S, Fox A, Walker K, Urban L: Intrathecally administered endotoxin or cytokines produce allodynia, hyperalgesia and changes in spinal cord neuronal responses to nociceptive stimuli in the rat. Eur J Pain 2000;4:247-257.

43 Wang CX, Olschowka JA, Wrathall JR: Increase of interleukin-1beta mRNA and protein in the spinal cord following experimental traumatic injury in the rat. Brain Res 1997;759:190-196

44 Zhang RX, Li A, Liu B, Wang L, Ren K, Zhang H, Berman BM, Lao L: IL-1ra alleviates inflammatory hyperalgesia through preventing phosphorylation of NMDA receptor NR-1 subunit in rats. Pain 2008;135 232-239.

45 Woolf CJ, Allchorne A, Safieh-Garabedian B, Poole S: Cytokines, nerve growth factor and inflammatory hyperalgesia: the contribution of tumour necrosis factor alpha. Br J Pharmacol 1997;121:417-424.

46 Hao S, Mata M, Glorioso JC, Fink DJ: Gene transfer to interfere with TNFalpha signaling in neuropathic pain. Gene Ther 2007;14 1010-1016

47 Schwetz I, McRoberts JA, Coutinho SV, Bradesi S, Gale G, Fanselow M, Million M, Ohning G, Tache Y, Plotsky PM, Mayer EA: Corticotropin-releasing factor receptor 1 mediates acute and delayed stress-induced visceral hyperalgesia in maternally separated long-evans rats. Am J Physiol Gastrointest Liver Physiol 2005;289:G704-G712.

48 Banks WA, Erickson MA: The blood-brain barrier and immune function and dysfunction. Neurobiol Dis 2011;37:26-32.

49 Maier SF, Watkins LR, Fleshner M: Psychoneuroimmunology. The interface between behavior, brain, and immunity. Am Psychol 1994;49:1004-1017.
50 Romeo HE, Tio DL, Rahman SU, Chiappelli F, Taylor AN: The glossopharyngeal nerve as a novel pathway in immune-to-brain communication: relevance to neuroimmune surveillance of the oral cavity. J Neuroimmunol 2001;115:91-100.

51 Persidsky Y, Stins M, Way D, Witte MH, Weinand M, Kim KS, Bock P, Gendelman HE, Fiala M: A model for monocyte migration through the blood-brain barrier during HIV-1 encephalitis. J Immunol 1997;158: 3499-3510.

52 Verma S, Nakaoke R, Dohgu S, Banks WA: Release of cytokines by brain endothelial cells: a polarized response to lipopolysaccharide. Brain Behav Immun 2006;20:449-455.

53 Maness LM, Banks WA, Zadina JE, Kastin AJ: Selective transport of blood-borne interleukin-1 alpha into the posterior division of the septum of the mouse brain. Brain Res 1995;700:83-88.

54 Arima Y, Harada M, Kamimura D, Park JH, Kawano F, Yull FE, Kawamoto T, Iwakura Y, Betz UA, Marquez G, Blackwell TS, Ohira Y, Hirano T, Murakami M: Regional neural activation defines a gateway for autoreactive $t$ cells to cross the blood-brain barrier. Cell 2012;148:447-457.

55 Nagasawa K, Chiba H, Fujita H, Kojima T, Saito T, Endo T, Sawada N: Possible involvement of gap junctions in the barrier function of tight junctions of brain and lung endothelial cells. J Cell Physiol 2006;208:123-132.

56 Cronin M, Anderson PN, Cook JE, Green CR, Becker DL: Blocking connexin43 expression reduces inflammation and improves functional recovery after spinal cord injury. Mol Cell Neurosci 2008;39:152-160.

57 Takeda M, Tanimoto T, Kadoi J, Nasu M, Takahashi M, Kitagawa J, Matsumoto S: Enhanced excitability of nociceptive trigeminal ganglion neurons by satellite glial cytokine following peripheral inflammation. Pain 2007; 129:155-166.

58 Zhang X, Chen Y, Wang C, Huang LY: Neuronal somatic atp release triggers neuronsatellite glial cell communication in dorsal root ganglia. Proc Natl Acad Sci USA 2007; 104:9864-9869.

59 Bielefeldt K, Lamb K, Gebhart GF: Convergence of sensory pathways in the development of somatic and visceral hypersensitivity. Am J Physiol Gastrointest Liver Physiol 2006;291:G658-G665.

60 Huang TY, Belzer V, Hanani M: Gap junctions in dorsal root ganglia: possible contribution to visceral pain. Eur J Pain 2011;14:49 e41-e11. 